\title{
Fabienne Bercegol, Chateaubriand: une poétique de la tentation
}

Fabio Vasarri

\section{(2) OpenEdition}

1 Journals

\section{Edizione digitale}

URL: http://journals.openedition.org/studifrancesi/6326

DOI: $10.4000 /$ studifrancesi.6326

ISSN: 2421-5856

\section{Editore}

Rosenberg \& Sellier

\section{Edizione cartacea}

Data di pubblicazione: 1 novembre 2010

Paginazione: 562-563

ISSN: 0039-2944

\section{Notizia bibliografica digitale}

Fabio Vasarri, «Fabienne Bercegol, Chateaubriand: une poétique de la tentation», Studi Francesi [Online],

162 (LIV | III) | 2010, online dal 30 novembre 2015, consultato il 08 janvier 2021. URL: http://

journals.openedition.org/studifrancesi/6326 ; DOI: https://doi.org/10.4000/studifrancesi.6326

Questo documento è stato generato automaticamente il 8 janvier 2021.

\section{(c) $(1) \&$}

Studi Francesi è distribuita con Licenza Creative Commons Attribuzione - Non commerciale - Non opere derivate 4.0 Internazionale. 


\title{
Fabienne Bercegol, Chateaubriand: une poétique de la tentation
}

\author{
Fabio Vasarri
}

\section{NOTIZIA}

FABIENNE BERCEGOL, Chateaubriand: une poétique de la tentation, Paris, Éditions Classiques Garnier, 2009, pp. 703.

1 Il denso volume di Fabienne Bercegol è il primo studio completo dedicato all'intera produzione narrativa di Chateaubriand (romanzi brevi ed epopee), esaminata principalmente nella prospettiva della tematica amorosa. All'abbondanza degli studi dedicati ai singoli testi non corrispondeva infatti finora un'analisi complessiva, che desse conto di un percorso trentennale (dall'ultimo decennio del Settecento al 1826). Nella trattazione, l'A. si sforza di chiarire il debito verso la produzione anteriore, classica e recente, proponendo accostamenti pertinenti (dal Cantico dei cantici a Madame de La Fayette, da Prévost a Sade). Un'attenzione costante è riservata ai valori ritmici e metrici della prosa dell'Enchanteur. Un'ulteriore questione che si ripropone nei diversi capitoli riguarda il controverso statuto narratologico dei testi, in un autore condizionato da un pregiudizio passatista nei confronti del genere borghese per eccellenza. Infine, lo studio è sorretto da un impianto solido e da una documentazione amplissima, che, insieme ai motivi appena accennati, gli assicurano un valore di bilancio critico.

2 L'introduzione parte dalla narrazione retrospettiva della scoperta della sessualità nei Mémoires d'outre-tombe, parallela all'iniziazione letteraria dell'adolescente. Ma la rivalutazione del patrimonio cristiano da parte dell'emigrato sposta la sfera erotica in una dimensione di tentazione e di colpa. Chateaubriand ambisce a superare lo psicologismo del romanzo settecentesco per considerare le passioni (passions è all'epoca il termine più usato nel linguaggio affettivo) in una prospettiva metafisica. La suggestione principale proviene da Agostino, dal suo tentativo di fusione di 
platonesimo e cristianesimo (caritas come sintesi di eros e agape, pp. 20-21). Partendo da queste premesse, un'ampia sezione del volume è dedicata alla poetica amorosa del Génie $d u$ christianisme. È noto tuttavia che l'ambizioso programma del restauratore del cristianesimo non trova piena applicazione nelle opere narrative, anteriori ma anche posteriori al Génie, che presentano vistosi residui di una passionalità violenta e distruttiva. Nelle sue minuziose analisi delle singole opere, l'A. dà un giusto rilievo alla persistenza della dimensione pulsionale.

3 La forza del desiderio si manifesta più intensamente nei Natchez, opera concepita prima del ritorno alla religione e più svincolata delle altre dai meccanismi dell'autocensura, nonostante la parziale riscrittura epica data alle stampe nel 1826. L'universo amerindiano è il regno di un eros polimorfo e barbaro, che declina le varianti più scandalose della casistica amorosa (promiscuità, omosessualità, sadismo, feticismo, necrofilia). La tradizione libertina vi è ripresa e dirottata in una direzione disforica, nel generale naufragio degli ideali illuministici.

4 Atala e René sono riportati alla loro complessità contraddittoria di tentativi falliti di sublimazione delle passioni, in particolare incestuose. Fabienne Bercegol riprende suggestioni precedenti che vanno in questa direzione (Jean-Claude Berchet, Pierre Glaudes, Michel Delon), prolungandole con sviluppi interessanti: il rovescio ambiguo e subdolo di Atala (pp. 362-363); la componente libresca della tematica incestuosa e l'importanza, sul piano biografico, della sorella Julie de Chateaubriand, oltre che della più nota Lucile (pp. 366-367); il vague des passions di René che si confonde, anche etimologicamente, con un vacuum, un vuoto che minaccia di risucchiare il soggetto (pp. 468 e 475).

5 Lo sforzo di sublimazione si fa più ancora più avvertibile nelle ultime opere di finzione, segnate dalla tentazione eroica (titolo della sezione relativa) e dal sublime tragico seicentesco. Nei Martyrs, l'esaltazione dell'amore coniugale è a sua volta trascesa in amore divino, secondo il modello corneliano di Polyeucte; mentre le Aventures du dernier Abencérage illustrano un percorso che dalla prodezza del Cid conduce alla rinuncia di Bérénice. L'autosacrificio dei personaggi principali ribadisce la visione pessimista delle passioni, ereditata dal giansenismo, ma la sublimazione appare anche in questo settore lacunosa e imperfetta.

6 Frustrazione e melanconia sono i tratti principali di una concezione del desiderio che, insieme all'intuizione di una componente intrinsecamente malefica, Chateaubriand trasmette a Baudelaire o a Barbey d'Aurevilly. La sua è una narrativa compensatoria, idealizzante, che si rivela impraticabile di fronte alla definitiva presa di coscienza della scomparsa della distanza classica e dell'evoluzione letteraria in direzione realisticoborghese. Un tentativo di «réenchanter le monde» (p. 657) accompagnato da una lucida consapevolezza della vanità dell'impresa. La bella conclusione di Fabienne Bercegol mostra il superamento del "romanesque" idealizzato nei Mémoires, sostituito da un'ironia complessa, fatta di distacco e partecipazione. 